\title{
Cervical carcinoma: prognosis in younger patients
}

\author{
J M RUSSELL, V BLAIR, R D HUNTER
}

\begin{abstract}
Retrospective analysis of 2870 patients with invasive carcinoma of the cervix treated by radiotherapy from 1971 to 1978 showed that the prognosis for younger patients (defined as either under 35 or under 40) was better than that for older age groups, but young patients presented with earlier disease. When the effect of stage on prognosis was also considered the improved survival of patients under 35 was confirmed, although the result was of only borderline significance. The better survival of younger patients was particularly noticeable for stage IB disease, the corrected five year survival of those under 35 being $93 \%$ compared with $79 \%$ for those over 35 .

On the basis of this analysis and a review of previous reports it is concluded that age alone is a poor indicator of prognosis and should not be used as an indication for adjuvant treatment. There is no evidence in this series of an aggressive form of cervical carcinoma in younger patients during the 1970s.
\end{abstract}

\section{Introduction}

The incidence of carcinoma of the cervix has increased among younger patients. Among women aged 25-34 new registrations in England and Wales have increased from $8 \cdot 6 / 100000$ in 1971 to $16 \cdot 1 /$ 100000 in $1981 .{ }^{12}$ The effect of age on survival is not clear, although many authors claim an adverse prognosis for younger women..$^{3.8}$ The present report describes the experience at this hospital from 1971 to 1978.

\section{Patients and methods}

From 1971 to 1978,3385 patients with carcinoma of the cervix were referred to this hospital; of these, 328 had already received treatment for

Departments of Radiotherapy and Medical Statistics, Christie Hospital and Holt Radium Institute, Manchester M20 9BX

J M RUSSELL, MRCP, FRCR, senior registrar in radiotherapy

V BLAIR, MSC, statistician

R D HUNTER, MRCP, FRCR, consultant radiotherapist

Correspondence to: Dr Russell.

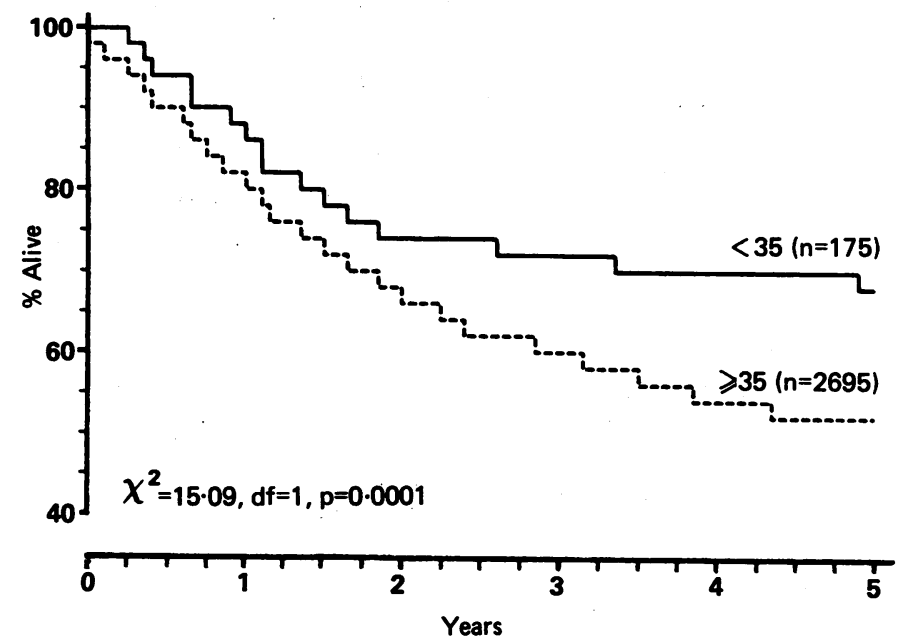

their disease elsewhere. Of the 3057 previously untreated patients, 187 were not treated as they were elderly and in generally poor health, had stage IV disease that was unlikely to benefit from palliative treatment, or had moved outside the region. There were thus 2870 previously untreated patients who received some form of radical or palliative treatment. The records of all these patients with carcinoma of the cervix that had been proved histologically were reviewed. Staging was by the classification of the International Federation of Gynaecology and Obstetrics based on clinical examination with and without anaesthesia. ${ }^{9}$ Intravenous urography, ultrasonography, or cystoscopy was not routinely performed unless symptoms suggested involvement of the urinary tract.

The survival rates for the younger patients with stage I disease proved better than expected, and we postulated that a disproportionate number of these patients might have a very early carcinoma compared with older patients. Some patients had been referred whose pathological report indicated a depth of invasion of $3 \mathrm{~mm}$ or less but who had received inadequate treatment for a stage IA (microinvasive) carcinoma or whose general condition precluded operative treatment. Stage I disease was therefore retrospectively subdivided into three groups: stage IA, asymptomatic disease with microinvasion, the clinical findings not excluding the possibility of a true stage IA tumour; stage IB (occult), histologically invasive cancer that could not be diagnosed by routine clinical examination alone; and true stage IB tumours. The pathological appearances were not reviewed routinely in this large series. When doubt remained about the true subdivision of stage I disease patients were assigned to the earlier subdivision. Stage IB (occult) tumours were grouped with stage IB for further analysis.

Treatment was predominantly by radiotherapy alone by the techniques of the Manchester school. ${ }^{10}$ In small volume tumours in stages I and IIA treatment was by intracavity radium alone, while in bulky stage I and IIA tumours and in other stages both intracavity radium and megavoltage external beam radiotherapy were used. Remote afterloading treatment was not available at this time. Radiation treatment was not given routinely after Wertheim hysterectomy, and patients referred after this procedure were not included in the series. In a few cases in which intracavity radium could not be given for technical reasons patients were referred for surgery. Chemotherapy was not used in the primary management of any patients with curable disease and was used in only a limited way for recurrent or metastatic disease.

Patients were followed up for a minimum of five years or until death, except for 44 patients lost to follow up before five years: of six aged under 35 , one had stage IB disease, four stage II, and one stage III; of 38 aged 35 and over, one had stage IA disease, nine stage IB, 19 stage II, seven stage III, and two stage IV. All results were corrected for intercurrent deaths. Survival curves were calculated by the life table method ${ }^{11}$ and compared by the log rank test. ${ }^{12}$ The relative risk of death and confidence intervals were calculated for the stratification into two groups. ${ }^{1 s}$

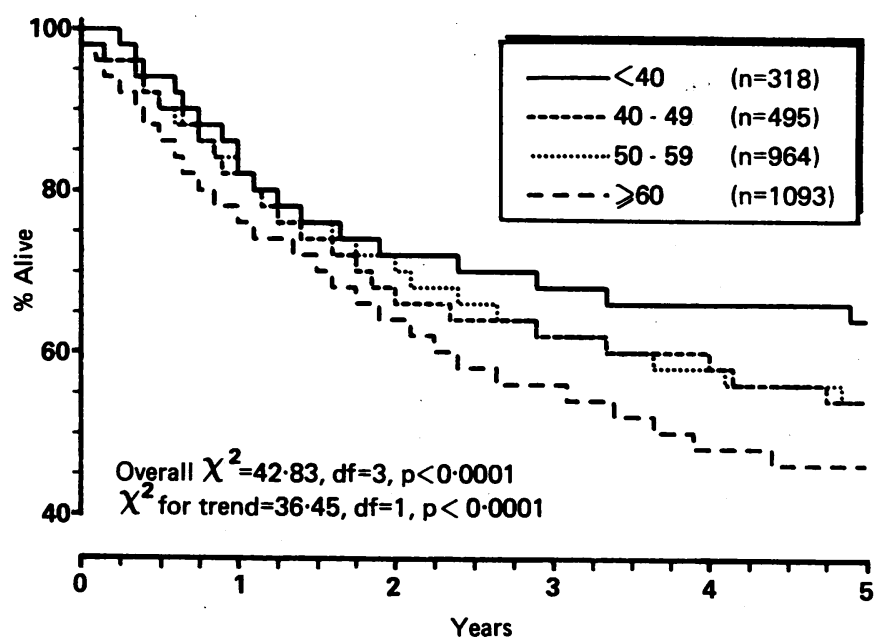




\section{Results}

The overall results for all patients, by stage, showed a five year corrected survival of $\mathbf{8 1} \cdot \mathbf{3} \%$ for stage I disease, $\mathbf{5 7 \cdot 8 \%}$ for stage II, $\mathbf{3 4} \cdot \mathbf{7} \%$ for stage III, and $9 \cdot 8 \%$ for stage IV.

Stratification for age was carried out in two forms to allow comparison with previous results: under 35 and 35 and over; and under 40, 40-49, 50-59, and 60 and over. When similar results were found with both methods of analysis only the latter stratification is shown. Survival curves stratified in both ways (fig 1 ) showed that younger patients had a better prognosis, the result being highly significant ( $p=0.0001$ or less). Proportionately more young patients, however, presented at the earlier stages, and survival was therefore considered within each stage. Table I shows the five year survival results overall and for each stage.

Only 34 patients were registered as having stage IA disease, with only one death from carcinoma. It is impossible to detect a true difference in survival between groups containing only 34 patients and one death. For patients with stage IB disease, including 30 with stage IB (occult) tumours, there was a significantly improved prognosis for younger patients compared with older age groups (fig 2). The corrected five year survival for patients under 35 was $93 \%$, compared with $79 \%$ for those over $35(p=0.02)$; for those under 40 it was $86 \cdot 5 \%$.

In stage II disease there was no significant difference between those aged under 35 and 35 and over (fig $3 ; p>0 \cdot 99$ ), but the result reached significance when the other stratification was used $(p=0.02)$. This, however, reflected a

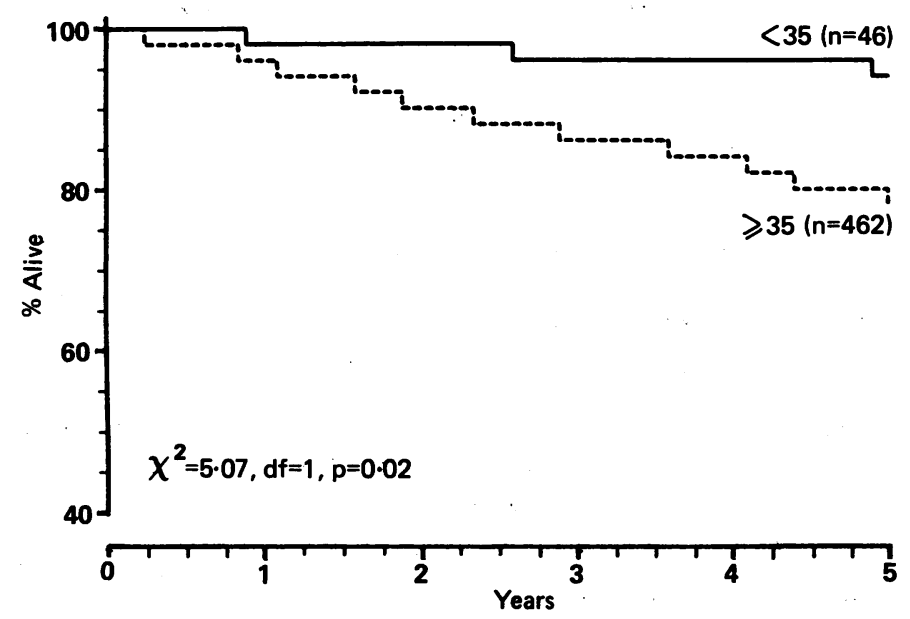

TABLE I-Corrected five year survival (percentage) for all patients depending on whether classification was into two or four age groups

\begin{tabular}{|c|c|c|c|c|c|c|}
\hline \multirow[b]{2}{*}{ Age (years) } & \multicolumn{6}{|c|}{ Stage } \\
\hline & IA & IB & II & III & IV & All \\
\hline \multicolumn{7}{|c|}{ Classification into two age groups } \\
\hline$<35$ & $\begin{array}{c}100 \\
(n=8)\end{array}$ & $\begin{array}{c}93 \\
(n=46)\end{array}$ & $\begin{array}{c}62 \\
(n=88)\end{array}$ & $\begin{array}{c}50 \\
(n=28)\end{array}$ & $\underset{(n=5)}{20}$ & $\begin{array}{c}69 \\
(n=175)\end{array}$ \\
\hline$\geqslant 35$ & $\begin{array}{c}96 \\
(n=26)\end{array}$ & $\begin{array}{c}79 \\
(n=462)\end{array}$ & $\begin{array}{c}57 \cdot 5 \\
(\mathrm{n}=1231)\end{array}$ & $\begin{array}{c}34 \\
(n=760)\end{array}$ & $\begin{array}{c}9 \cdot 5 \\
(n=216)\end{array}$ & $\begin{array}{c}51 \\
(n=2695)\end{array}$ \\
\hline \multicolumn{7}{|c|}{ Classification into four age groups } \\
\hline$<40$ & $\begin{array}{c}94 \\
(n=17)\end{array}$ & $\begin{array}{c}86 \cdot 5 \\
(\mathrm{n}=90)\end{array}$ & $\begin{array}{c}60 \\
(n=153)\end{array}$ & $\begin{array}{c}40 \\
(n=48)\end{array}$ & $\begin{array}{c}20 \\
(n=10)\end{array}$ & $\begin{array}{c}65 \\
(n=318)\end{array}$ \\
\hline $40-49$ & $\begin{array}{c}100 \\
(n=9)\end{array}$ & $\begin{array}{c}81 \\
(n=93)\end{array}$ & $\begin{array}{c}63 \\
(n=229)\end{array}$ & $\begin{array}{c}33 \\
(n=121)\end{array}$ & $\begin{array}{c}6 \\
(n=43)\end{array}$ & $\begin{array}{c}55 \\
(n=495)\end{array}$ \\
\hline $50-59$ & $\begin{array}{c}100 \\
(n=5)\end{array}$ & $\begin{array}{c}81 \\
(n=173)\end{array}$ & $\begin{array}{c}61 \\
(n=461)\end{array}$ & $\begin{array}{c}37 \\
(\mathrm{n}=254)\end{array}$ & $\begin{array}{c}10 \\
(n=71)\end{array}$ & $\begin{array}{c}54 \\
(n=964)\end{array}$ \\
\hline$\geqslant 60$ & $\begin{array}{c}100 \\
(n=3)\end{array}$ & $\begin{array}{c}75 \\
(n=152)\end{array}$ & $\begin{array}{c}52 \\
(n=476)\end{array}$ & $\begin{array}{c}33 \\
(n=365)\end{array}$ & $\begin{array}{c}10 \\
(n=97)\end{array}$ & $\begin{array}{c}45 \\
(n=1093)\end{array}$ \\
\hline
\end{tabular}

poorer prognosis for the oldest age group, while patients aged 40-59 had an improved survival; the prognosis for the youngest patients was the average for stage II. The results in stages III and IV showed no significant difference between the various age groups (figs 4 and 5).

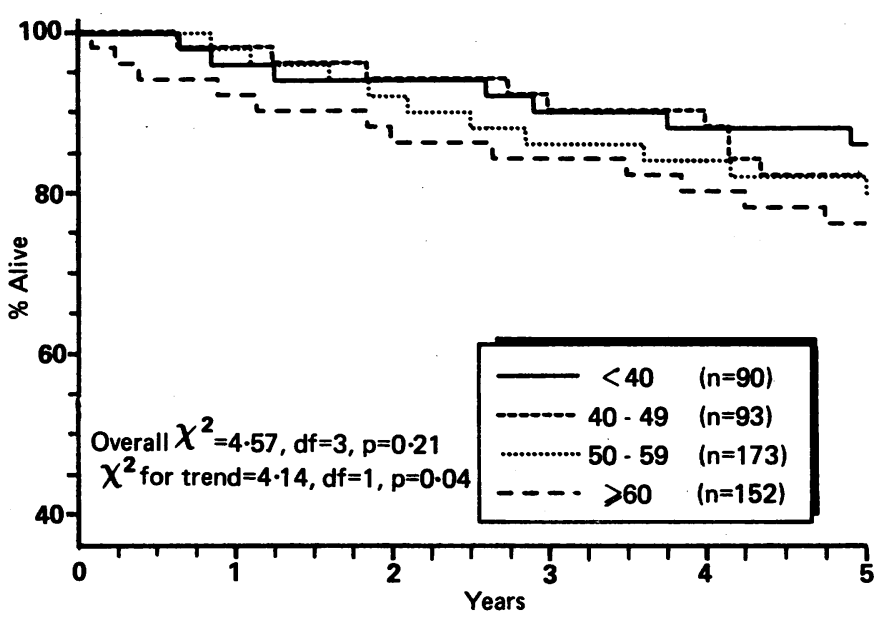

FIG 2-Corrected survival curves for patients with stage IB disease classified into two and four age groups.
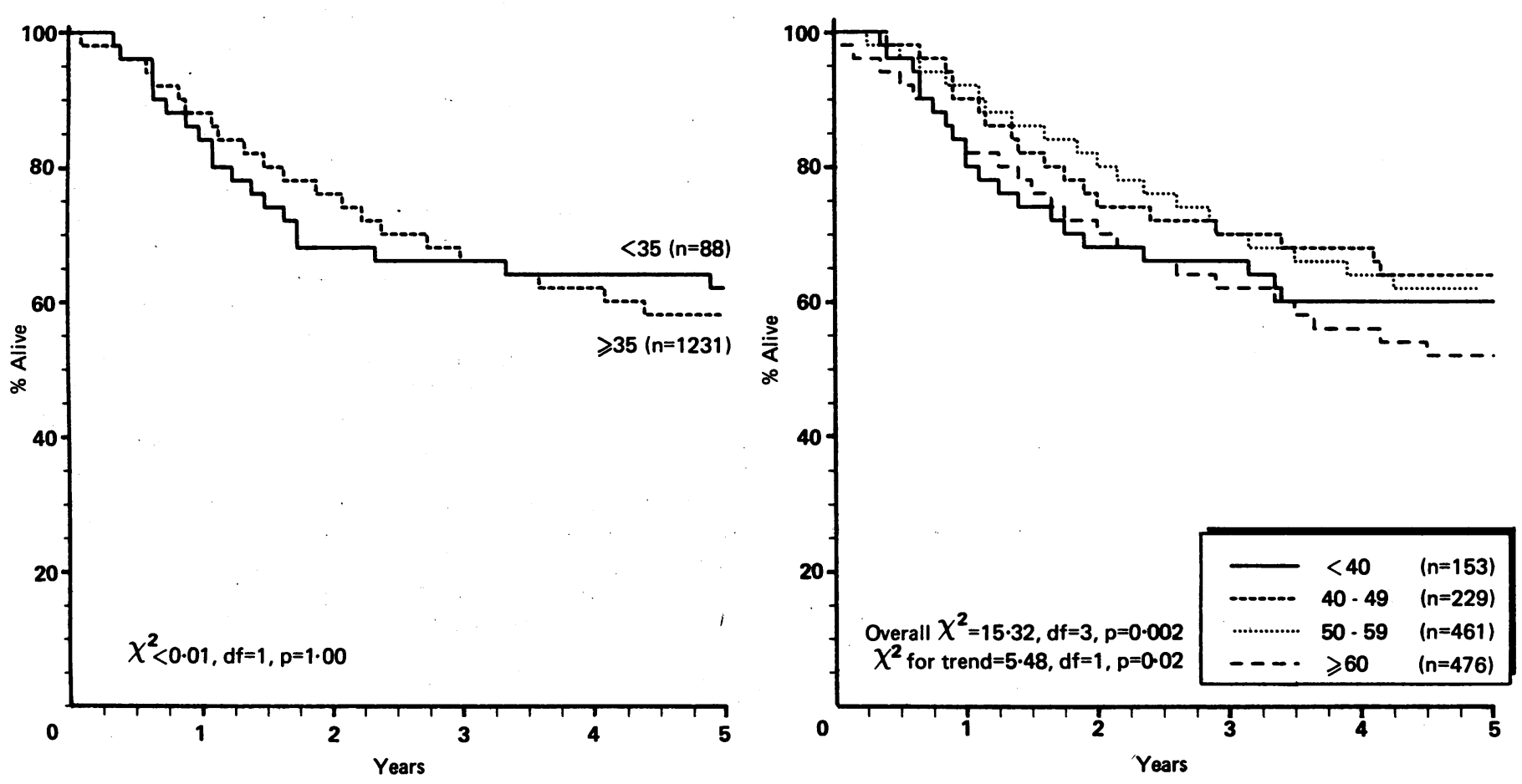

FIG 3-Corrected survival curves for patients with stage II disease classified into two and four age groups. 
When the data were considered for all patients by age and allowing for stage the result was of borderline significance $\left(\chi^{2}=3 \cdot 29, \mathrm{df}=1, \mathrm{p}=0.0695\right)$ when stratification was by those under and over 35 , but it reached significance when stratification was into more age bands (overall $\chi^{2}=7 \cdot 98$, $\mathrm{df}=3, \mathrm{p}=0.05 ; \chi^{2}$ for trend $=4.65, \mathrm{df}=1, \mathrm{p}=0.03$ ). Again the oldest age group had a poorer survival while the prognosis in the three other age bands was about equal.

Table II shows the relative risk of death in the under 35 age group compared with those 35 and over, together with $95 \%$ confidence intervals, in each stage (except for stage IA) and overall. The observed risk of death in the younger age group was $20 \%$ less than that in the older age group. The results were compatible with a true risk of death ranging from a reduction of $37 \%$ to an increase of $1 \%$ in the younger age group compared with the older group.

\section{Discussion}

In this study patients aged under 35 with carcinoma of the cervix treated by radical radiotherapy had a better overall prognosis than older patients, but a higher proportion of young patients presented with earlier stage tumours. When the effect of stage was considered younger patients still fared better than women over 35, although this result was of only borderline significance. The main factor affecting the prognosis of women under 35 was the survival of those with stage IB disease. The treatment techniques used within each stage were basically similar over the whole age range except that a few elderly patients and any patient in generally poor health had a less radical form of management.

The possibility that a more aggressive, rapidly progressive tumour occurs in younger patients has been suggested,,$^{3-8}$ but little evidence to support this view was found in this study of patients treated by radical radiotherapy during the 1970s. From 1971 to 1978

TABLE II-Relative risk of death and 95\% confidence intervals in those aged under 35 compared with those aged 35 and over

\begin{tabular}{lccccc}
\hline $\begin{array}{l}\text { Stage of } \\
\text { disease }\end{array}$ & $\begin{array}{c}\text { Observed } \\
\text { No of deaths }\end{array}$ & $\begin{array}{c}\text { Extent of } \\
\text { exposure to risk } \\
\text { of death }\end{array}$ & Variance & $\begin{array}{c}\text { Relative risk of } \\
\text { death }\end{array}$ & $\begin{array}{c}95 \% \\
\text { Confidence } \\
\text { intervals }\end{array}$ \\
\hline IB & 3 & 10.37 & 9.30 & 0.45 & 0.24 to 0.86 \\
II & 36 & 36.67 & 33.87 & 0.98 & 0.70 to 1.37 \\
III & 14 & 20.25 & 19.01 & 0.72 & 0.46 to 1.13 \\
IV & 4 & 4.78 & 4.31 & 0.83 & 0.32 to 2.13 \\
All & 57 & 72.32 & 66.67 & 0.8 & 0.63 to 1.01 \\
\hline
\end{tabular}

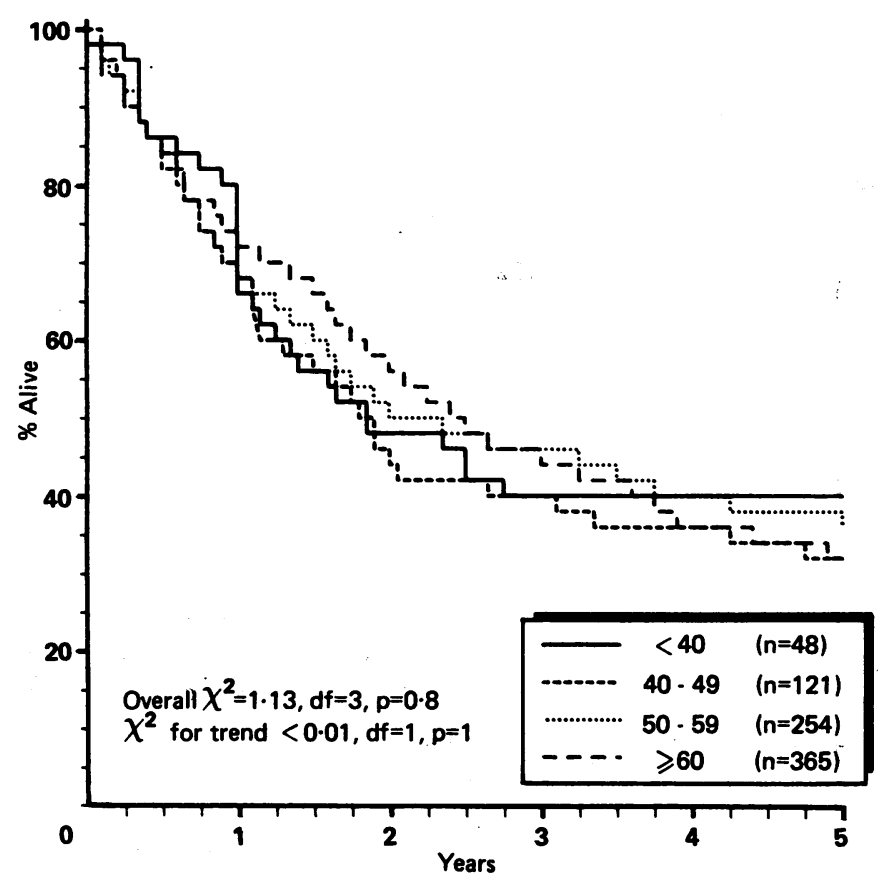

FIG 4-Corrected survival curves for patients with stage III disease classified into four age groups.

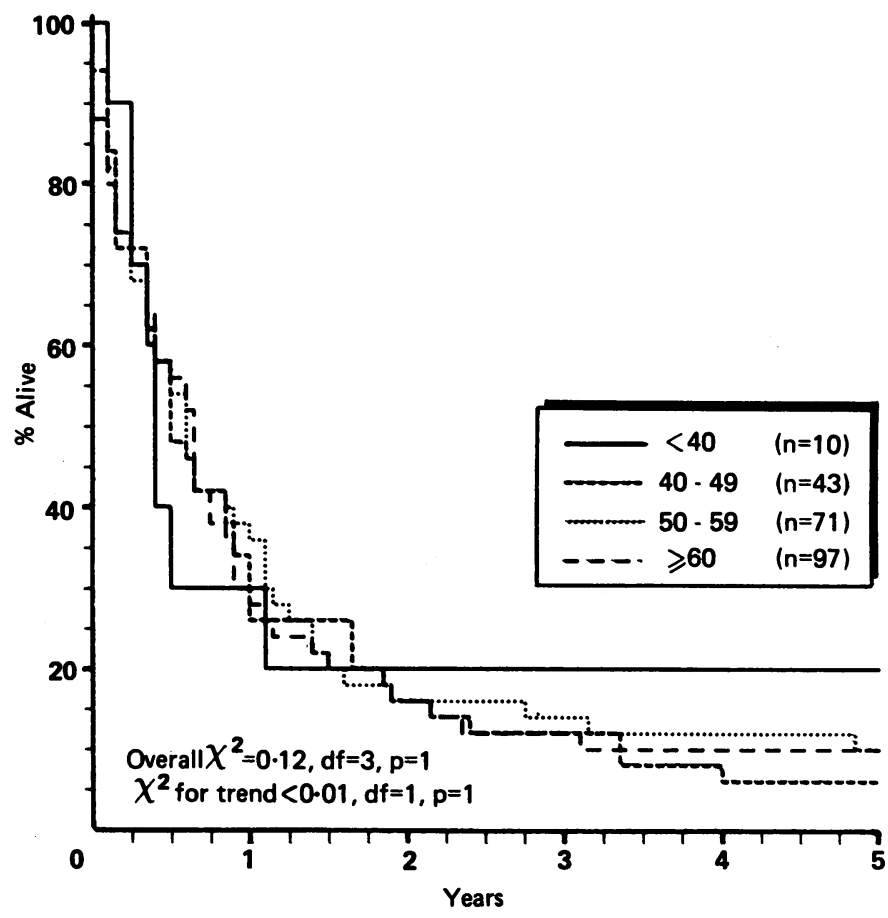

FIG 5-Corrected survival curves for patients with stage IV disease classified into four age groups.

new referrals of patients with cervical cancer to this centre did not increase in the under $\mathbf{4 0}$ age group, but the greater acceptance of cervical screening in this group and consequent earlier presentation may have contributed to the better prognosis for stage IB disease.

Previous studies did not suggest that age was a reliable prognostic indicator: younger women were variously stated to have a poorer prognosis than older women, ${ }^{3-8}$ a better prognosis, ${ }^{14-16}$ or the same survival rates. ${ }^{17-27}$ Among surgical series in early stage disease Sidhu et al reported a reduced survival in patients aged 45 or less with cervical cancer treated by radical (Wertheim) hysterectomy with pelvic lymphadenectomy, noting also an increased incidence of lymph node metastases. ${ }^{5}$ Conversely, all 25 patients aged 35 or less in the series of Berkowitz et al were still disease free at one to four years' follow up. ${ }^{25}$ In the larger series of Baltzer et al from West Germany ( 980 patients with squamous carcinoma) no significant difference in survival was found between those aged 35 years or less and those over 35.27

Similar results were found in the more numerous larger series in which intracavity radium and external beam radiotherapy were used. Lindell reviewed early reports and noted their differing findings. ${ }^{3}$ His review of the extensive experience of the Radiumhemmet in Stockholm from 1914 to 1944 showed that their younger patients had a poorer prognosis at all stages of disease. In a later series Kottmeier found a poorer prognosis not only in younger patients (20-30 years) but also in those aged 60 years or older. ${ }^{4}$ This was confirmed in a smaller series by Turunen and Vara. ${ }^{28}$

Stanhope et al, considering 1085 patients treated mainly by radiotherapy at the $M D$ Anderson Hospital, noted a significant decrease in five year survival for patients under the age of 35 at most stages, notably stage IIB, but not at stages IA and IV ${ }^{6} \mathrm{~A}$ later report from the same centre, however, primarily on the role of lymphangiography, did not find age an important variable. ${ }^{26}$ Prempree et $a l$, with 94 patients under 40 years in a total of 561 patients treated at the University of Maryland Hospital, Baltimore, found a significantly poorer survival in those under $\mathbf{4 0}$ and particularly under $\mathbf{3 0}$ (although only small numbers were studied). ${ }^{7}$ Age was not, however, a significant prognostic factor when the effect of stage was excluded in an earlier series from the Johns Hopkins Hospital, also in Baltimore. ${ }^{18}$ Mendenhall $e t$ al found younger age a fairly weak adverse prognostic feature for pelvic control in stages IB, IIA, and IIB, but it influenced pelvic control more strongly when considered in conjunction with tumour size and packed cell volume. ${ }^{8}$ Gusberg 
and Herman in a smaller series from New York did not confirm that age is of prognostic importance, ${ }^{20}$ nor did van Voorhis in a series of 762 patients from Iowa. ${ }^{21}$ An early series in which radium alone was used failed to find any prognostic value in age. ${ }^{19}$

Series in which both surgery and radiotherapy have been given have not found age a significant factor in prognosis, ${ }^{17}{ }^{22-24}$ and indeed Gynning et al noted a different effect of age when two different treatment techniques were used for stage IB tumours (radical radiotherapy alone, both intracavity and external beam, or radical radiotherapy followed by elective hysterectomy). ${ }^{29}$ Other radiotherapy series have found that the effect of age on survival varies with stage. ${ }^{30} 31$

These divergent and potentially confusing findings must result, at least in part, from the effect of other prognostic factors. Age alone does not adequately indicate prognosis even when the effect of stage is also considered. In this study there was no evidence that young patients with cervical cancer treated by radical radiotherapy during the 1970s had a more aggressive form of malignancy. In most stages of disease their prognosis was similar to that of older patients, and in stage IB it was considerably better. We therefore conclude that younger age alone is not an indication for adjuvant treatment for cervical cancer.

We thank Mr R Swindell, department of medical statistics, for help with statistical analysis, and the department of medical illustration, Christie Hospital, for producing the figures.

\section{References}

1 Office of Population Censuses and Surveys. Cancer statistics: registrations. England and Wales 1971. London: HMSO, 1979.

Office of Population Censuses and Surveys. Cancer statistics: registrations. England and Wales 1981 London: HMSO, 1985.

Lindell A. Carcinoma of the uterine cervix; incidence and influence of age. Acta Radiol 1952;supp 92:1-102.

Kottmeier H-L. Surgical and radiation treatment of carcinoma of the uterine cervix. Acta Obstet Gynecol Scand 1964;43(suppl 2): 1-48.

5 Sidhu GS, Koss LG, Barber HRK. Relation of histologic factors to the response of stage I epidermoid carcinoma of the cervix to surgical treatment. Obstet Gynecol 1970;35:329-38.

6 Stanhope CR, Smith JP, Wharton JT, Rutledge FN, Fletcher GH, Gallager HS. Carcinoma of the cervix: the effect of age on survival. Gynecol Oncol 1980;10:188-93.
7 Prempree T, Patanaphan V, Sewchand W, Scott RM. The influence of patients' age and tumor grade on the prognosis of carcinoma of the cervix. Cancer 1983;51:1764-71.

8 Mendenhall WM, Thar TL, Bova FJ, Marcus RB, Morgan LS, Million RR. Prognostic and treatment factors affecting pelvic control of stage IB and IIA-B carcinoma of the intact uterine

9 International Federation of Gynaecology and Obstetrics. Classification and staging of malignant tumours in the female pelvis. Acta Obstet Gynecol Scand 1971;50:1-7.

10 Cole MP, Hunter RD. Cancer of the cervix uteri. In: Easson EC, Pointon RCS, eds. The radiotherapy of malignamt disease. Berlin, Heidelberg: Springer-Verlag, 1985:281-301.

11 Kaplan EL, Meier P. Non-parametric estimation from incomplete observations. Journal of the American Statistical Association 1958;53:457-81.

12 Peto R, Pike MC, Armitage P, et al. Design and analysis of randomized clinical trials requiring prolonged observation of each patient. II. Analysis and examples. Br $\mathcal{J}$ Cancer 1977;35:1-39.

13 Cox DR. Regression models and life tables. Journal of the Royal Statistical Society, Series B 1972;34:187-220.

14 Ashley DJB. Evidence for the existence of two forms of cervical carcinoma. Journal of Obstetrics and Gynaecology of the British Commonwealth 1966;73:382-9.

15 Cancer Registry of Norway. Survival of cancer patients: cases diagnosed in Norway 1953-1967. Oslo: Norwegian Cancer Society, 1975:93-6.

16 Futoran RJ, Nolan JF. Stage I carcinoma of the uterine cervix in patients under 40 years of age. Am $\mathcal{J}$ Obstet Gynecol 1976;125:790-7.

17 Decker DG, Fricke RE, Pratt JH. Invasive carcinoma of the cervix in young women. FAMA 1955;158:1417-20.

18 Brack CB, Townsend L, Haines BW, Dickson RJ. Cervical cancer: factors influencing prognosis in intraepithelial and clinical carcinoma of the cervix uteri. Obstet Gynecol 1956;8:728-35.

19 Maliphant RG. Variations in the malignancy of cancers of the uterine cervix. Foumal of Obstetrics and Gynaecology of the British Empire 1960;67:420-8.

20 Gusberg SB, Herman GG. Radiosensitivity and virulence factors in cervical cancer. Am $\mathcal{F}$ Obstet Gynecol 1968;100:627-39.

21 Van Voorhis LW. Carcinoma of the cervix. I. Therapeutic and patient factors affecting survival. Am $\mathcal{O}$ Obstet Gynecol 1970;108:105-14.

22 Kyriakos M, Kempson RL, Perez CA. Carcinoma of the cervix in young women. I. Invasive carcinoma. Obstet Gynecol 1971;38:930-44.

23 Rampone JF, Klem V, Kolstad P. Combined treatment of stage IB carcinoma of the cervix. Obstet Gynecol 1973;41:163-7.

24 Kjorstad KE. Carcinoma of the cervix in the young patient. Obstet Gynecol 1977;50:28-30.

25 Berkowitz RS, Ehrmann RL, Lavizzo-Mourey R, Knapp RC. Invasive cervical carcinoma in young women. Gynecol Oncol 1979;8:311-6.

26 Hammond JA, Herson J, Freedman RS, et al. The impact of lymph node status on survival in cervical carcinoma. In $\mathcal{Y}$ Radiat Oncol Biol Phys 1981;7:1713-8.

27 Baltzer J, Koepcke W, Lohe KJ, Ober KG, Zander J. Age and 5-year survival rates in patients with operated carcinoma of the cervix. Gynecol Oncol 1982;14:220-4.

28 Turunen A, Vara P. Results of the surgical and radiological treatment of carcinoma of the cervix at the Women's Clinic, University of Helsinki, in 1953-1958. Acta Obstet Gynecol Scand the Women's Clinic,

29 Gynning I, Johnsson J-E, Alm P, Tropé C. Age and prognosis in stage IB squamous cell carcinoma of the uterine cervix. Gynecol Oncol 1983;15:18-26.

30 Blomfield GW, Cherry CP, Glucksmann A. Biological factors influencing the radiotherapeutic results in carcinoma of the cervix. Br $\mathcal{F}$ Radiol 1965;38:241-54.

31 Walter L, Glucksmann A, Cherry CP. Biological and physical factors in the radiotherapy of carcinoma of the cervix. Fournal of Obstetrics and Gynaecology of the British Commonwealth 1965;72:575-85.

(Accepted 15 May 1987)

\begin{abstract}
Recently qualitative tests have indicated that gastrointestinal bleeding during exercise may be an important contributory factor in sports anaemia. In six healthy men who walked $37 \mathrm{~km}$ on four consecutive days faecal haemoglobin content remained normal (reference range $0 \cdot 10-2.53 \mathrm{mg} / \mathrm{g}$ faeces) with no significant differences between values. In 28 marathon runners who refrained from taking drugs or food containing blood the median faecal haemoglobin content increased by $0.42 \mathrm{mg} / \mathrm{g}$ faeces $(95 \%$ confidence interval 0.12 to $0.83 \mathrm{mg} / \mathrm{g})$ from $1.06(0.86$ to 1.31$) \mathrm{mg} / \mathrm{g}$
\end{abstract}

University Medical School, Foresterhill, Aberdeen AB9 2ZD

J D ROBERTSON, BSC, PHD, research fellow, department of environmental and occupational medicine

R J MAUGHAN, BSC, PHD, lecturer, department of environmental and occupational medicine

R J L DAVIDSON, FRCP, FRCPATH, senior lecturer, haematology unit

Correspondence to: Dr Davidson. before the race. In 13 runners who had taken drugs before the race the corresponding increase in the median faecal haemoglobin content was $0.87(-0.03$ to 2.20$) \mathrm{mg} / \mathrm{g}$ from the value before the race of $0.93(0.46$ to 1.55$) \mathrm{mg} / \mathrm{g}$.

Prolonged walking had no effect on gastrointestinal blood loss. Intense endurance exercise in the form of marathon running induced a significant but clinically unimportant increase. This may be exaggerated by the ingestion of drugs and assume importance in causing iron deficiency and sports anaemia. The use of drugs, particularly analgesics, by marathon runners should be actively discouraged.

\section{Introduction}

Sports or runners' anaemia is a well recognised complication of endurance exercise and has been variously attributed to plasma volume expansion, traumatic red cell haemolysis, and iron deficiency. This iron deficiency has been ascribed to haematuria, haemoglobinuria, iron loss through excessive sweating, impaired iron absorption, and, more recently, occult gastrointestinal blood 